\title{
Mastitis alert preferences of farmers milking with automatic milking systems
}

\author{
H. Mollenhorst, ${ }^{\star 1,2}$ L. J. Rijkaart, $†$ and H. Hogeveen ${ }^{\star} \dagger$ \\ *Department of Farm Animal Health, Faculty of Veterinary Medicine, Utrecht University, PO Box 80151, 3508 TD Utrecht, the Netherlands \\ †Business Economics Group, Wageningen University, PO Box 8130, 6700 EW Wageningen, the Netherlands
}

\begin{abstract}
The aim of this study was to assess farmers' preferences for the performance characteristics of mastitis detection systems. Additionally, we looked at whether certain groups of farmers could be distinguished with specific preferences. Farmers' opinions concerning mastitis detection systems, as well as general information about the farm and the farmer, were investigated with a standard questionnaire. The second part of the questionnaire was specifically aimed at elucidating preferences. Definitions of time windows and performance parameters, such as sensitivity and specificity, were incorporated into characteristics of a detection system (attributes) that reflect farmers' daily experience. Based on data from 139 farmers, we concluded that, on average, they prefer a clinical mastitis detection system that produces a low number of false alerts, while alerting in good time and with emphasis on the more severe cases. These 3 attributes were evaluated as more important than the 3 other attributes, representing the costs of the detection system, the number of missed cases, and how long before clinical signs alerts need to be given. Variation in importance per attribute, however, was high, denoting that farmers' preferences differ considerably. Although some significant relationships were found between farm characteristics and attributes, no clear groups of farmers with specific preferences could be distinguished. Based on these results, we advise making detection systems adaptable for the farmers to satisfy their preferences and to match the circumstances on the farm. Furthermore, these results support that for evaluation of detection algorithms comparisons have to be made at high levels of specificity (e.g., 99\%) and time windows have to be kept small (preferably no more than $24 \mathrm{~h}$ ).
\end{abstract}

Key words: adaptive conjoint analysis, automatic milking system, farmer preference, mastitis detection

Received September 29, 2011.

Accepted January 16, 2012.

${ }^{1}$ Corresponding author: erwin.mollenhorst@wur.nl

${ }^{2}$ Current address: Animal Production Systems Group, Wageningen University, PO Box 338, 6700 AH Wageningen, the Netherlands.

\section{INTRODUCTION}

Detection of clinical mastitis $(\mathbf{C M})$ is one of the critical factors in automatic milking systems (AMS) and one that needs to be improved considerably (Hogeveen et al., 2010). Because the farmer is not present during the milking process, it is not possible to strip before milking and check the milk visually. This has to be replaced by an automatic mastitis detection system, which consists of sensors that measure certain properties of the milk [e.g., electrical conductivity (EC), color of the milk, or milk yield] and an algorithm that transforms data into alerts. Much research has been done in the past decades on the development of better sensors and algorithms (e.g., Maatje et al., 1992; Espada and Vijverberg, 2002; Whyte et al., 2004; Chagunda et al., 2006; Kamphuis, 2010; Steeneveld, 2010).

When evaluating detection systems, epidemiological parameters are often used to characterize detection performance. Sensitivity and specificity are the most common parameters, but also prevalence-sensitive parameters like success rate (synonym for positive predictive value) and false alert rate are used (for definitions, see Hogeveen et al., 2010). For all of these performance parameters, however, it is necessary to properly define the gold standard, including a time window. As Mein and Rasmussen (2008) discuss, no general consensus exists about what the real gold standard is, not even among researchers. Furthermore, almost every study has used a different time window (see for an overview Hogeveen et al., 2010), which means that alerts (or observations of $\mathrm{CM}$, or both) stay valid for different periods of time. The differences in gold standard definition and time window make a fair comparison difficult.

The end users of the detection systems, however, are the farmers, and they seem to be forgotten in the discussion, except that some researchers indicate that farmers are annoyed by the high number of false-positive alerts and would prefer the number of false alerts to be decreased (e.g., Claycomb et al., 2009; Kamphuis, 2010; Steeneveld et al., 2010). In the current study, we wanted to investigate which performance parameters are valued highest by the farmers themselves. To do so, definitions of performance parameters and time windows had to be incorporated into clear characteristics 
Table 1. Descriptive categorical variables used in the study

\begin{tabular}{|c|c|}
\hline Variable name & Description (classes) \\
\hline Character & $\begin{array}{l}\text { Does the farmer characterize himself as precise? (I want to have everything in perfect order; } \\
\text { When I have spare time, I will try to get everything in perfect order; Just take action when } \\
\text { needed. No preventive measures; My method of working could be much neater) }\end{array}$ \\
\hline Age & Age of respondent (below 30; 30 to $40 ; 41$ to $55 ;$ above 56 yr of age) \\
\hline Education & Level of education of respondent [lower (technical); secondary; higher education] \\
\hline Identity & Identity of the respondent [(co-)owner; employee or family member $]$ \\
\hline Successor & $\begin{array}{l}\text { When respondent is (co-)owner, does (s)he have a successor? [(probably) yes; (probably) no; } \\
\text { do not know; respondents who were not owners were placed in a separate class) }\end{array}$ \\
\hline Mastitis situation & Perceived mastitis situation [problematic; controllable (average); good] \\
\hline Main indicator & Most preferred indicator used for detecting CM $(A M S ; n o n-A M S)^{1}$ \\
\hline Second indicator & Second most preferred indicator used for detecting CM $(A M S ; \text { non- } A M S)^{1}$ \\
\hline Region & Province in which farm is located (regrouped to North; South; East; West) \\
\hline Grazing system & Grazing system applied (regrouped to no grazing; only day or night; day and night) \\
\hline
\end{tabular}

${ }^{1}$ The question was asked with more possible answers that were regrouped before analysis; SCC estimation on AMS, color, electrical conductivity, milk production, alerts list udder health, alerts list visiting pattern, and weight loss were classified as AMS; SCC from test-day records and visual observations of the cows were classified as non-AMS.

of a detection system. These characteristics must be presented so that, subsequently, their utility could be quantified. When farmers' preferences, as represented by the utility values, are known, objectives for research and development could be defined accordingly.

The aim of this study was to assess farmers' preferences for performance characteristics of mastitis detection systems. Additionally, we looked at whether certain groups of farmers could be distinguished with specific preferences.

\section{MATERIALS AND METHODS}

\section{Data Collection}

From a customer (farmer) database of Lely Industries NV (Maassluis, the Netherlands), a manufacturer of AMS, 480 farmers were selected to be invited to complete the questionnaire. These 480 farmers were selected by taking a random stratified sample. The strata included were years of experience in milking with an AMS, defined as year of first purchase (before 2005, in the years 2005 to 2009 , or from 2009 onwards) and the region farmers lived in (4 regions, covering all of the Netherlands, were defined, based on postal code).

The farmers were invited by letter to participate in the questionnaire. As a first step, the farmers were asked to send us an e-mail with farm size, number of years of experience with AMS, and whether or not they wanted to participate. Besides explaining the aims of the study, the letter offered a reward for participationa gift voucher (€20) - to help motivate farmers to participate. Farmers who agreed to participate were sent a user name, password, and the link to the web-based questionnaire by e-mail.

\section{Questionnaire}

Farmers' opinions concerning mastitis detection systems, as well as general information about the farm and the farmer, were investigated with a standard questionnaire. Questions were asked about, for example, farm size, labor, bulk tank SCC, actual mastitis situation at the farm, information sources used for detecting CM, level of education, age, experience, and farmer attitude (precise or not). Details of the variables and classes are given in Table 1 for the categorical variables and in Table 2 for the continuous variables.

The second part of the questionnaire, specifically aimed at elucidating preferences, consisted of an adaptive conjoint analysis (ACA; Sawtooth Software Inc., 2011). This is a method adopted from marketing research that determines desirable features (and price) of a new product. A product is assumed to comprise characteristics (named attributes), each with its own levels (e.g., color is an attribute with black, white, or red as levels). First, ACA asks for consumer preference for levels within each attribute, and importance of each attribute. With this information, each level of each attribute receives a utility value. Using and updating these utilities, paired questions are asked (preferences of levels between each attribute are determined) resulting in final utility values, which can be compared with each other. The importance of an attribute is calculated from the difference in utility value of the most and least preferred level of that attribute in comparison to the other attributes. Concluding, ACA computes consumer utility values for each level within an attribute. The utility value of a complete product is then assumed to be the sum of the utilities for each level of each attribute the product comprises. More details on the 
Table 2. Descriptive continuous variables used in the study

\begin{tabular}{lll}
\hline Variable name $^{1}$ & Unit & Description \\
\hline Number of cows & $\mathrm{n}$ & Number of cows (milking and dry cows, excluding young stock) \\
Number of AMS & $\mathrm{n}$ & Number of boxes of the AMS \\
AMS occupation & Cows per AMS & Number of cows divided by number of AMS \\
Milk quota & $1,000 \mathrm{~kg} / \mathrm{yr}$ & Milk quota of the farm \\
Production level & $1,000 \mathrm{~kg}$ of milk per cow & Milk quota divided by number of cows \\
BTSCC & 1,000 cells $/ \mathrm{mL}$ & Average BTSCC of the past year \\
Labor per cow & $\mathrm{h} /$ cow per day & Hours of labor in and around the barn per cow per day \\
Labor used for cows & $\%$ & Fraction of total available labor used in and around the barn \\
Severe cases of CM & $\%$ & Fraction of CM cases being severely sick cows \\
Sick cases of CM & $\%$ & Fraction of CM cases being sick cows \\
Mild cases of CM & $\%$ & Fraction of CM cases being not sick, but only having some flakes in the milk \\
CM incidence & Cases per 100 cows per year & Number of cases per year recalculated to a 100-cow herd \\
Control intensity & Checks per 100 cows per week & Number of visual checks per week recalculated to a 100-cow herd \\
\hline
\end{tabular}

${ }^{1} \mathrm{AMS}=$ automatic milking system; BTSCC $=$ bulk tank $\mathrm{SCC} ; \mathrm{CM}=$ clinical mastitis.

ACA methodology can be found in technical papers of Sawtooth Software Inc. (2007).

In this study, an ACA was performed testing farmers' preferences concerning alerts from mastitis detection systems. Attributes were selected by a combination of literature research and expert knowledge. Expert knowledge was gathered through a brainstorming session and through feedback from the audience at a conference (annual meeting of the Dutch Mastitis Research Workers on November 30, 2010 in Utrecht, the Netherlands).

Definitions of time windows and performance parameters, such as sensitivity and specificity, have to be incorporated into characteristics of a detection system that could be recognized by the farmers. These characteristics have to reflect farmers' daily experience. The sensitivity of a detection system affects the number of CM cows missed by that system, whereas the gold standard definition on which the detection system is based relates to the health status of those missed CM cows. Specificity affects the number of false alerts a farmer receives (false positives). First of all, it is quite annoying (decrease in pleasure at work) for the farmer to get a lot of false alerts and, as a consequence, it can decrease the trust in the detection system. The time window also has consequences on when the farmer receives the first alert. Thus, alerts received after the onset of CM will cause postponement of treatment and, thereby, reduced effectiveness of treatment. Alerts received before CM can induce proactive behavior and may, therefore, be desirable for the farmer or they may be perceived as false alerts because no clinical signs have appeared, as yet. Furthermore, variable costs are involved, because newly developed sensors [e.g., assessing SCC (Whyte et al., 2004) or lactate dehydrogenase (Mazeris, 2010)] often use a milk sample and add reagent, whereas conventional sensors (e.g., measuring EC) are able to operate within the milk flow without any additional costs per milking. All 6 attributes: time after, time before, costs, number of false alerts, number of missed cows, and severity of missed cows, with their respective levels are defined in Table 3.

When the questionnaire was fully developed, 2 AMS farmers that were not part of the 480 invited farmers, were asked to test it. Their feedback was used to ensure that all questions were clearly stated, before invitations were sent out for the web-based questionnaire.

\section{Statistical Analysis}

The sum of the importance of the 6 attributes per respondent equals $100 \%$. Thus, the importance of the attributes had to be tested with a method that takes

Table 3. Description of the attributes and their levels

\begin{tabular}{ll}
\hline Attribute & Description (levels) \\
\hline Time after & First alert is given at most this amount of time after cow actually has $\mathrm{CM}^{1}(0,24,48 \mathrm{~h})$ \\
Time before & First alert is given at most this amount of time before cow actually has CM $(0,24,48 \mathrm{~h})$ \\
Costs & Variable costs of detection per year $(300,600,1,200 €)^{2}$ \\
False alerts & Number of false alerts per day $(1,3,5,10)^{2}$ \\
Number missed & Number of missed cows per year $(2,4,6)^{2}$ \\
Severity missed & Health status of most severely affected missed cow [not sick (only flakes in milk), sick, severely sick] \\
${ }^{1} \mathrm{CM}=$ clinical mastitis. & \\
${ }^{2}$ Based on a farm size of 65 cows. Three versions of the questionnaire $(65,130$, and 195 cows) were made with adapted numbers to approach \\
reality for the farmers. Furthermore, a table was provided with intermediate and larger farm size.
\end{tabular}


Table 4. Farm characteristics for checking representativeness of study population $(\mathrm{n}=139)$

\begin{tabular}{|c|c|c|c|c|c|}
\hline Parameter & $\begin{array}{l}\text { Current } \\
\text { study }\end{array}$ & $\begin{array}{c}5 \text { th } \\
\text { percentile }\end{array}$ & $\begin{array}{c}95 \text { th } \\
\text { percentile }\end{array}$ & Sample $1^{1}$ & Sample $2^{2}$ \\
\hline Number of cows & 98 & 46 & 180 & 85 & 96 \\
\hline Milk quota $(\times 1,000 \mathrm{~kg})$ & 859 & 400 & 1,600 & 796 & $\mathrm{NA}^{3}$ \\
\hline Mastitis incidence (cases per 100 cows per year) & 20.4 & 5.0 & 46.4 & 26 & NA \\
\hline Number of AMS $^{6}$ & 1.6 & 1 & 3 & 1.6 & NA \\
\hline
\end{tabular}

${ }^{1}$ Dohmen et al. (2010).

${ }^{2}$ Hogenkamp (2011).

${ }^{3}$ Not available.

${ }^{4}$ BTSCC $=$ bulk tank SCC [self-reported in this study, recalculated from milk production recording data per cow for Dohmen et al. (2010), and based on data from the management program Agrovision (Agrovision BV, Deventer, the Netherlands) for Hogenkamp (2011)].

${ }^{5} \mathrm{n}=137$, because for 2 farms no reliable BTSCC was available.

${ }^{6} \mathrm{AMS}=$ automatic milking system.

into account the fact that the values are not independent. Accordingly, generalized estimating equations with farmer as repeated subject, importance as dependent variable, and attribute (detection system characteristic) as independent variable were used to assess whether, on average, some attributes were considered to be more important than others.

Whether relationships existed between the importance of the attributes and those of the characteristics of the farm was determined by general linear models with the importance of the attribute as dependent and farm characteristic as independent variable. Univariable models were considered to be statistically significant at $P<0.05$. Differences between all classes of a characteristic were tested with a Bonferroni $t$-test.

To assess whether some farm characteristics had additive or interactive effects on the importance of the attribute, multivariable models were tested. All independent variables with $P<0.20$ from the univariable models were included and manual backward elimination was performed until all remaining variables contributed significantly at $P<0.05$. Finally, one-way interactions were tested among the remaining variables.

Probability plots (Q-Q plots) were assessed to check normality of variance and did not reveal any problems. All statistical analyses were performed with SAS 9.2 software (SAS Institute Inc., Cary, NC).

\section{RESULTS}

\section{Response}

Of the 480 farmers approached, 176 (37\%) initially agreed to participate and received the questionnaire by e-mail. Finally 139 farmers (out of 176; 79\%) completed the questionnaire. These farmers were compared with 2 other samples (Dohmen et al., 2010; Hogenkamp, 2011) of Dutch AMS farms to check whether they were representative of the population (Table 4). Farms in this study were somewhat larger, on average. Somatic cell count was self-reported in this study and somewhat lower than in the other 2 samples. Clinical mastitis incidence was also lower in this study, compared with the incidence reported in Dohmen et al. (2010), and self-reported in both studies, which may suggest better udder health on the farms in our sample.

\section{Importance of Attributes}

When farmers were indifferent, the preference for each attribute was $16.7 \%$. The farmers considered the attributes time after $(18.7 \% \pm 0.60$; estimate $\pm \mathrm{SE})$, number of false alerts $(20.2 \% \pm 0.59)$, and severity of missed cows $(19.4 \% \pm 0.60)$ to be more important than the other 3 attributes (Figure 1). Within these attributes, the levels $0 \mathrm{~h}$ after, 1 false alert per $\mathrm{d}$, and not sick, respectively, got the highest utility values. As 15 pairwise comparisons between attributes were performed, the significance level was adjusted with a Bonferroni correction to $P<0.0033$.

\section{Farm Characteristics}

Table 5 shows the $P$-values for the significant relations between categorical farm characteristics (Table 1) and single attributes (Table 3). All significant differences between classes are described below. Farmers using an AMS equipped with SCC estimation $(\mathrm{n}=5$; variable detection system) seemed to ascribe more value to the attribute time before ( 8.0 percentage points difference in importance; $95 \%$ CI: 1.5 to 14.5 ) compared with farmers using an AMS without SCC estimation. This difference, however, was caused by 1 farmer (out of 5) who considered this attribute very important (37.4\%), scoring a very low utility for an alert up to 48 $\mathrm{h}$ before actual CM. Deleting this record removed the significant difference. Farmers using AMS data as the main indicator for $\mathrm{CM}$ detection $(\mathrm{n}=110)$ ascribed less 


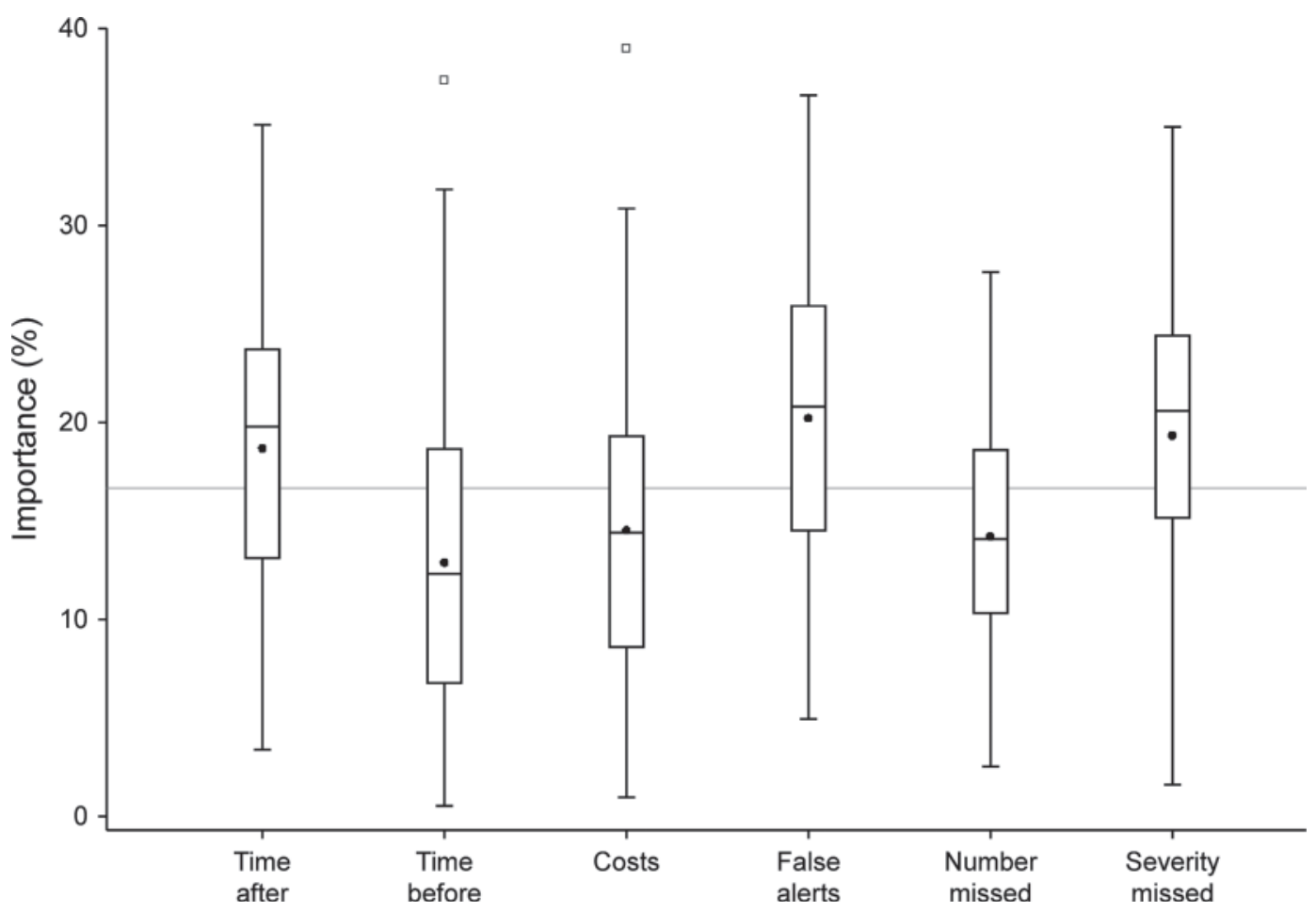

Figure 1. Box-and-whiskers plot of the importance $(\%)$ of the attributes with a reference line at $16.7 \%$, representing equal importance. The dots represent the means, the boxes represent the lower and upper quartiles and the medians, the serifs of the whiskers represent the minimum and maximum values within 1.5 times the interquartile range of the quartiles, and squares represent observations outside 1.5 times the interquartile range of the quartiles.

value to the attribute costs $(-3.4$ percentage points difference in importance; $95 \%$ CI: -6.4 to -0.4 ), whereas they ascribed more value to the attribute time before (3.2 percentage points difference in importance; $95 \%$ CI: 0.2 to 6.2 ), compared with farmers mainly using non-AMS data. No difference existed, however, between how long before actual CM they wished to receive the alerts [chi-squared test, $P>0.05$ for main indicator by preferred level $(0,24$, or $48 \mathrm{~h})]$. Farmers who perceived the mastitis situation on their farm as good $(\mathrm{n}=32)$ ascribed significantly more value $(6.6$ percentage points difference in importance; $95 \%$ CI: 1.4 to 11.8 ) to the number of missed cases than farmers who perceived the mastitis situation as problematic $(\mathrm{n}=9)$. Farmers who characterized themselves as very precise ("I want to have everything in perfect order"; $\mathrm{n}=60$ ) ascribed significantly more value to the attribute time before (6.6 percentage points difference in importance; $95 \%$ CI: 0.8 to 12.5 ) and less to the attribute number of false alerts $(-6.3$ percentage points difference in importance; $95 \%$ CI: -11.9 to -0.7 ) than farmers who characterized themselves as reactive ("Just take action when needed. No preventive measures"; $\mathrm{n}=13)$. Nonowners $(\mathrm{n}=7)$ ascribed significantly more value (8.1 percentage points difference in importance; $95 \%$ CI: 2.8 to 13.4$)$ to the severity of missed cows than did owners $(\mathrm{n}=132)$.
The group of nonowners was also fully responsible for the significant relationships for the variables experience and successor, which means that years of experience and whether there was a successor did not influence these results.

Table 6 shows the estimates, standard errors, and $P$ values for the significant relationships between continuous farm characteristics (Table 2) and single attributes (Table 3). With an increase in production level per cow of $1,000 \mathrm{~kg}$ of milk per year, the importance of number of false alerts decreased $1.15( \pm 0.57)$ percentage points. With an increase in AMS occupation of 1 cow per AMS, the importance of number of missed cows decreased $0.10( \pm 0.04)$ percentage points. With an increase in labor time used in and around the barn of 1 min per cow per day (i.e., $1 \mathrm{~h}$ per day for a 60 -cow herd), the importance of number of false alerts decreased $0.73( \pm 0.33)$ percentage points. With an increase in CM incidence of 1 percentage point, the importance of number of missed cows decreased $0.09( \pm 0.04)$ percentage points. Finally, with an increase in percentage of severe $\mathrm{CM}$ cases of 1 percentage point, the importance of the severity of missed cows decreased $0.08( \pm 0.04)$ percentage points.

Most individual variables account for less than $5 \%$ of the variance of the attributes, as measured by the coefficient of determination $\left(\mathrm{R}^{2}\right)$ values (data not shown) 
Table 5. $P$-values of relations between categorical independent variables and attributes ${ }^{1}$

\begin{tabular}{|c|c|c|c|c|c|c|}
\hline \multirow[b]{2}{*}{ Variable } & \multicolumn{6}{|c|}{ Attribute } \\
\hline & $\begin{array}{l}\text { Time } \\
\text { after }\end{array}$ & $\begin{array}{c}\text { Time } \\
\text { before }\end{array}$ & Costs & $\begin{array}{l}\text { False } \\
\text { alerts }\end{array}$ & $\begin{array}{c}\text { Number } \\
\text { missed }\end{array}$ & $\begin{array}{c}\text { Severity } \\
\text { missed }\end{array}$ \\
\hline Detection system & 0.26 & 0.02 & 0.07 & 0.77 & 0.90 & 0.89 \\
\hline Main indicator & 0.60 & 0.04 & 0.03 & 0.60 & 0.40 & 0.58 \\
\hline Mastitis situation & 0.17 & 0.19 & 0.96 & 0.98 & 0.01 & 0.06 \\
\hline Character & 0.34 & 0.02 & 0.33 & 0.01 & 0.25 & 0.91 \\
\hline Identity & 0.33 & 0.87 & 0.90 & 0.06 & 0.76 & 0.00 \\
\hline Experience & 0.61 & 0.26 & 0.54 & 0.11 & 0.59 & 0.03 \\
\hline Successor & 0.09 & 0.72 & 0.68 & 0.30 & 0.63 & 0.01 \\
\hline
\end{tabular}

of the univariable models. Only the perceived mastitis situation (number of missed CM cases), character of the farmer (time before and number of false alerts) and identity of the farmer (severity of missed CM cases) accounted for more (6 to $9 \%$ ) of the variance of the attributes mentioned.

The attribute time after had no statistically significant relationship with any of the independent variables. For the other attributes, 9 to $17 \%$ of the variance could be explained by 2 to 4 variables (Table 7 ). No significant interactions were discovered between independent variables and effects of individual variables remained similar to the effects in the univariable models and, therefore, are not explained again. Of the 36 variables with a probability between 0.05 and $0.20,2$ variables remained in the final models. Farmers who had a low $\mathrm{CM}$ incidence among their cows ascribed more value to the attribute time before, and farmers from the northern part of the Netherlands ascribed less value to costs than farmers from the south.

\section{DISCUSSION}

A final response rate of $29 \%$ (139 out of 480) seems to be low, but is quite well in line with other studies (e.g., Huijps et al., 2009, who reported a response rate of $21 \%$ ). As we had full addresses of the farmers, we were able to contact them for non-response analysis ( $\mathrm{n}=33$, but not all questions were answered by all farmers). Farmers who were not willing to participate, even after being reminded by a telephone call, were not different than responders in terms of farm size (cows and milk quota; $\mathrm{n}=15$, data not shown) and the main reason given for not participating was lack of time $(45 \%, 15$ out of 33$)$. Another important reason for a lower response rate was that the list of farmers was not corrected for those that had resigned from milking $(15 \%, 5$ out of 33$)$. The only factor, we think, that could have influenced the results is that non-responders indicated having a lack of time, which may have led to an underestimation of the importance of the attribute number of false alerts. On the other hand, this argument could also have been used as a simple excuse.

Based on a comparison between our sample and 2 other samples of Dutch AMS farms, an indication exists that udder health status could have been better in our sample than on the average farm with an AMS. However, we do not think that this influenced our results substantially, as the farm characteristics mastitis situation and CM incidence were only significantly related to 1 attribute each.

Two other factors with respect to the representativeness of the sample have to be kept in mind when interpreting these results. Only Dutch farmers milking

Table 6. Estimates (Est.), standard errors, and $P$-values of relations between continuous independent variables and attributes ${ }^{1}$

\begin{tabular}{|c|c|c|c|c|c|c|c|c|c|}
\hline Variable $^{2}$ & \multicolumn{9}{|c|}{ Attribute } \\
\hline Production level & -1.15 & 0.57 & 0.05 & & & 0.05 & & & 0.23 \\
\hline AMS occupation & & & 0.74 & -0.10 & 0.04 & 0.03 & & & 0.08 \\
\hline Labor per cow & -0.73 & 0.33 & 0.03 & & & 0.12 & & & 0.21 \\
\hline
\end{tabular}

${ }^{1}$ Only independent variables and attributes with at least 1 significant $(P<0.05$; boldface $)$ relation are shown.

${ }^{2} \mathrm{AMS}=$ automatic milking system; $\mathrm{CM}=$ clinical mastitis. 
Table 7. $F$-values and $P$-values of final multivariable models

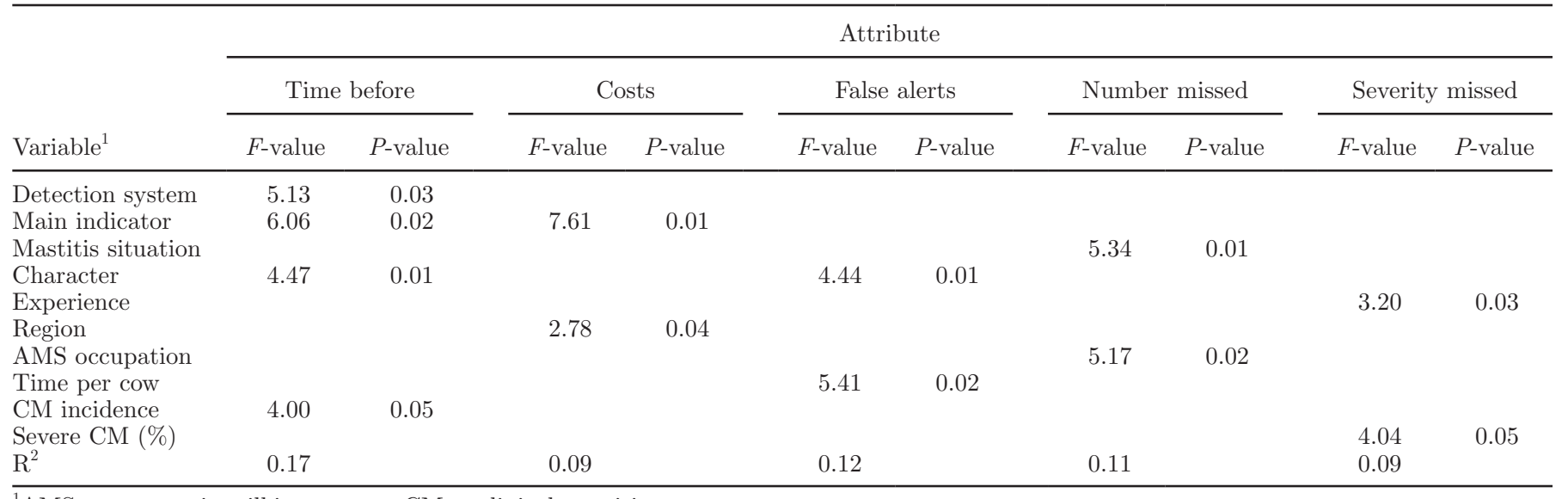

${ }^{1} \mathrm{AMS}=$ automatic milking system; $\mathrm{CM}=$ clinical mastitis.

with a Lely AMS were included in the sample. Because detection systems differ between brands, farmers that choose a Lely AMS might have different preferences than farmers choosing another brand of AMS. It is very hard, however, to assess the influence of these 2 factors (country and brand) on the final results. As no strong relationships could be found between farmer characteristics and alert preferences within the studied sample, it is doubtful whether this would be different if other types of AMS or other nationalities were included.

One of the crucial aspects in developing an ACA questionnaire is the definition of attributes and their levels. The range of levels within an attribute strongly influences the final importance ascribed to that attribute, as the importance is calculated from the difference in utility value of the most and least preferred level of that attribute in comparison to the other attributes. When the same attribute is included in the questionnaire with more extreme levels, it will definitely receive a higher importance.

Another crucial point is the assumption that attributes are uncorrelated. This point can be taken into account by the researchers while developing the questionnaire, but the respondents also have to be able to consider the attributes as independent. This could have been a problem in this study, as (at least some) farmers know that, in practice, sensitivity and specificity are highly interdependent for a given detection system. Furthermore, farms could, for example, have linked a higher price with a system with better performance. In the explanation to participants, we explicitly stressed that attributes have to be considered as independent, but it is not possible to check whether respondents succeeded in doing so. This could have led to difficulties for the program in estimating utility values and, subsequently, could have introduced some noise into the data set. This may have led to less clear results and underestimation of differences and effects of farm characteristics. No doubt exists, therefore, that differences and effects that were found to be significant are truly so.

Results showed that, on average, farmers would prefer a CM detection system that produces a low number of false alerts and gives alerts for the more severe cases and in good time (not too late for effective action to be taken). This is in line with the thoughts expressed in other studies (e.g., Claycomb et al., 2009; Kamphuis et al., 2010). For the ongoing discussion on a gold standard (Mein and Rasmussen, 2008) and time window (Sherlock et al., 2008; Hogeveen et al., 2010), this means that, when we want to involve farmers' preferences in our evaluations, time windows have to be kept small, preferably without any delay and with a maximum of $24 \mathrm{~h}$ before actual CM (preferred level for attribute time before), which is less than proposed by Claycomb et al. (2009). With respect to sensitivity and specificity it is recommended, in general, to focus on decreasing the number of false positive alerts (i.e., to increase specificity) first, while aiming to reach the minimum requirements of 70 and $99 \%$, respectively (Mein and Rasmussen, 2008). For evaluation studies, we, therefore, recommend comparing detection systems at a fixed specificity of $99 \%$. Furthermore, large variation was revealed, which could be interpreted as a need for farm-specific detection systems or systems having the possibility to adapt the settings according to preferences or farm circumstances.

Analysis of farm and farmer characteristics did not yield a very clear picture with distinct groups of farmers with different preferences. Furthermore, only less than $10 \%$ of the variance per attribute could be explained with single variables. In the multivariable analysis, $17 \%$ of the variance of the attribute time before could be explained by 4 variables. This attribute, however, was 
the most difficult one to interpret, as farmers did not seem to agree with each other as to which level $(0,24$, or $48 \mathrm{~h}$ before) was preferred.

Farmers who characterized themselves as reactive and used less time in and around the stable considered diminishing the number of false alerts to be more important. This confirms our expectation that farmers who pay less attention to their cows dislike false alerts the most. Only $12 \%$ of the variance for this attribute, however, could be explained by these variables, whereas no significant relationship with any of the other attributes could be found for hours of labor per cow and only one relationship (with time before) for character. It is, therefore, not clear which attributes these farmers consider as less important, and this made grouping of farmers very difficult.

\section{CONCLUSIONS}

Farmers, on average, prefer a CM detection system that produces a low number of false alerts, while alerting in good time and with emphasis on the more severe cases. Variation in importance per attribute, however, was high, denoting that farmers' preferences differ considerably. Although some significant relationships between farm characteristics and attributes (characteristics of the mastitis detection system) were found, no clear groups of farmers with specific preferences could be distinguished. Based on these results, we advise making $\mathrm{CM}$ detection systems adaptable for the farmers to satisfy their preferences and to match the circumstances on the farm. Furthermore, these results support that, for evaluation of detection algorithms, comparisons have to be made at high levels of specificity (e.g., 99\%) and time windows have to be kept small (preferably no more than $24 \mathrm{~h}$ ).

\section{ACKNOWLEDGMENTS}

We gratefully acknowledge the participating farmers for completing the questionnaire and Lely Industries NV (Maassluis, the Netherlands) for providing addresses. We also want to thank Aart de Groot for technical support and Jan van den Broek and Hans Vernooij (all from Utrecht University, Utrecht, the Netherlands) for statistical advice. This research was supported by the Dutch Technology Foundation (STW, Utrecht, the Netherlands), Applied Science Division of the Netherlands Organization for Scientific Research (NWO, The Hague, the Netherlands), and the Technology Program of the Ministry of Economic Affairs, Agriculture and Innovation (The Hague, the Netherlands).

\section{REFERENCES}

Chagunda, M. G. G., N. C. Friggens, M. D. Rasmussen, and T. Larsen. 2006. A model for detection of individual cow mastitis based on an indicator measured in milk. J. Dairy Sci. 89:2980-2998.

Claycomb, R. W., P. T. Johnstone, G. A. Mein, and R. A. Sherlock. 2009. An automated in-line clinical mastitis detection system using measurement of conductivity from foremilk of individual udder quarters. N. Z. Vet. J. 57:208-214.

Dohmen, W., F. Neijenhuis, and H. Hogeveen. 2010. Relationship between udder health and hygiene on farms with an automatic milking system. J. Dairy Sci. 93:4019-4033.

Espada, E., and H. Vijverberg. 2002. Milk colour analysis as a tool for the detection of abnormal milk. Page IV-28-IV-38 in The First North American Conference on Robotic Milking, Toronto, Canada. Wageningen Pers, Wageningen, the Netherlands.

Hogenkamp, W. 2011. Even pas op de plaats-Robotmelkers houden probleem met celgetal. Boerderij 96:22-24.

Hogeveen, H., C. Kamphuis, W. Steeneveld, and H. Mollenhorst. 2010. Sensors and clinical mastitis - The quest for the perfect alert. Sensors (Basel, Switzerland) 10:7991-8009.

Huijps, K., H. Hogeveen, T. J. G. M. Lam, and R. B. M. Huirne. 2009. Preferences of cost factors for mastitis management among Dutch dairy farmers using adaptive conjoint analysis. Prev. Vet. Med. 92:351-359.

Kamphuis, C. 2010. Making sense of sensor data: Detecting clinical mastitis in automatic milking systems. PhD Thesis. Faculty of Veterinary Medicine, Utrecht University, Utrecht, the Netherlands.

Kamphuis, C., H. Mollenhorst, J. A. P. Heesterbeek, and H. Hogeveen. 2010. Detection of clinical mastitis with sensor data from automatic milking systems is improved by using decision-tree induction. J. Dairy Sci. 93:3616-3627.

Maatje, K., P. J. M. Huijsmans, W. Rossing, and P. H. Hogewerf. 1992. The efficacy of in-line measurement of quarter milk electrical-conductivity, milk-yield and milk temperature for the detection of clinical and subclinical mastitis. Livest. Prod. Sci. 30:239-249.

Mazeris, F. 2010. DeLaval Herd Navigator proactive herd management. Pages 26-27 in The First North American Conference on Precision Dairy Management, Toronto, Canada. Accessed Mar. 7, 2012. http://www.precisiondairy2010.com/conferenceproceedings. htm.

Mein, G. A., and M. D. Rasmussen. 2008. Performance evaluation of systems for automated monitoring of udder health: Would the real gold standard please stand up? Pages 259-266 in Mastitis Control_-From Science to Practice. T. J. G. M. Lam, ed. Wageningen Academic Publishers, Wageningen, the Netherlands.

Sawtooth Software Inc. 2007. The ACA/Web v6.0 technical paper. Sawtooth Software Technical Paper Series. Sawtooth Software Inc., Sequim, WA.

Sawtooth Software Inc. 2011. SSI Web 7.0.22. Sawtooth Software Inc., Sequim, WA.

Sherlock, R., H. Hogeveen, G. Mein, and M. D. Rasmussen. 2008. Performance evaluation of systems for automated monitoring of udder health: Analytical issues and guidelines. Pages 275-282 in Mastitis Control-From Science to Practice. T. J. G. M. Lam, ed. Wageningen Academic Publishers, Wageningen, the Netherlands.

Steeneveld, W. 2010. Decision support for mastitis on farms with an automatic milking system. PhD Thesis. Faculty of Veterinary Medicine, Utrecht University, Utrecht, the Netherlands.

Steeneveld, W., L. C. van der Gaag, W. Ouweltjes, H. Mollenhorst, and H. Hogeveen. 2010. Discriminating between true-positive and false-positive clinical mastitis alerts from automatic milking systems. J. Dairy Sci. 93:2559-2568.

Whyte, D. S., R. G. Orchard, P. S. Cross, T. Frietsch, R. W. Claycomb, and G. A. Mein. 2004. An on-line somatic cell count sensor. Pages 235-240 in Automatic Milking: A Better Understanding. A. Meijering, H. Hogeveen, and C. J. A. M. de Koning, ed. Wageningen Academic Publishers, Wageningen, the Netherlands. 